\title{
Synthesis of Well Crystallized Cristobalite as a Reference Mineral
}

Key words: Cristobalite-Silicic acid-Synthesis-Reference mineral-X-ray diffractionCrystallinity

Inhalation of silica minerals sometimes has adverse health effects on workers exposed to dust. Cristobalite is a silica mineral formed in industrial processes such as brick-making and smelting operations, but few studies of its health effects have been made in comparison with those for quartz. Hence, accurate and precise determination of mineralogical characteristics and content is required to provide basic data on airborne cristobalite concentrations in work environments and to protect the health of workers.

Quantitative analysis of cristobalite has been done mostly by the X-ray powder diffraction (XRD) method, ${ }^{1-3)}$ but sometimes by infrared spectroscopy. ${ }^{4)}$ Inconsistency in the results of the XRD analysis has sometimes been recognized because of lack of a certified primary standard. ${ }^{2)}$ The abundance of pure and well crystallized cristobalite is much more limited in nature than that of quartz. A standard cristobalite for XRD analysis must therefore be prepared synthetically. It has been reported that cristobalite can be synthesized by heating quartz, ${ }^{1-3)}$ however, this quartz-cristobalite conversion synthesis is time-consuming for completion of the reaction (e.g., heating at $1500^{\circ} \mathrm{C}$ takes $48 \mathrm{h.}^{1)}$ ) On the other hand, transformation of amorphous silica by heating is also known to be a feasible method of making cristobalite. ${ }^{5-8}$ This method has the advantage of reducing reaction time ${ }^{5)}$ and avoiding any residue of the unreactive original crystalline phase.

Few studies, however, have concerned the details of techniques for preparing cristobalite using amorphous silica or its crystallinity. The following account reports experiments on the transformation of amorphous silica to cristobalite in an attempt to develop an effective procedure for making standard cristobalite as a reference mineral for XRD analysis.

For the starting material, silicic acid (n-hydrate) from Wako Pure Chemical Ind., Ltd., was selected. Loss on ignition was $48.21 \%$ and the content of impurities, non-volatile with $46 \%$ hydrofluoric acid, was $0.79 \%$. XRD analysis revealed that the silicic acid was in the amorphous state, and no crystalline phases were detected. The silicic acid was heated at various temperatures over the range $1000-1450^{\circ} \mathrm{C}$ for varying periods of time using a muffle furnace with a silicon carbide heating element. The procedure is as follows. Place a few grams of silicic acid in a $10-\mathrm{ml}$ platinum crucible. After placing the crucible in 


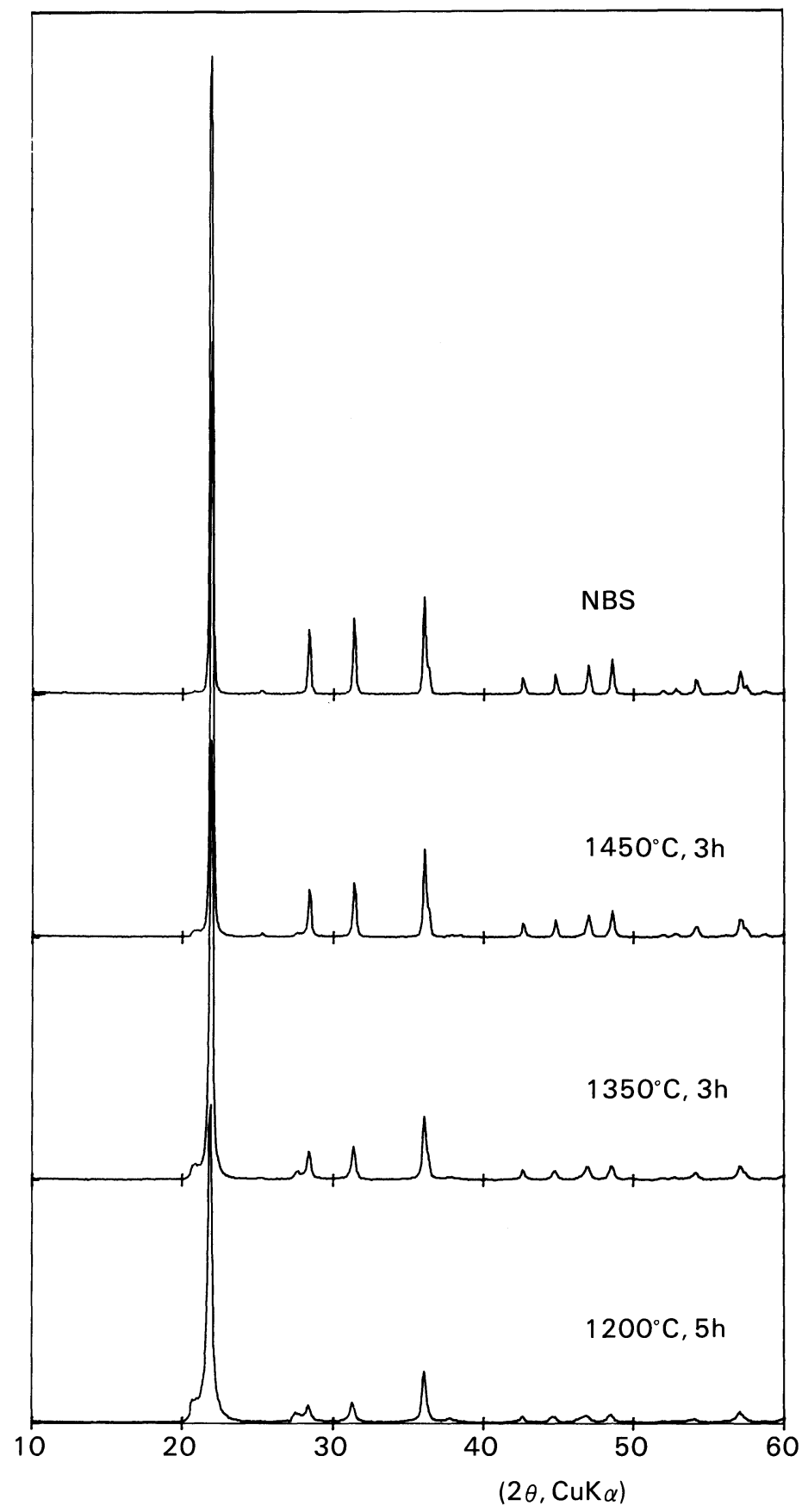

Fig. 1. X-ray powder diffraction patterns of cristobalite formed from silicic acid at different temperatures and heating times. NBS: NBS respirable cristobalite (NBS SRM 1879). 

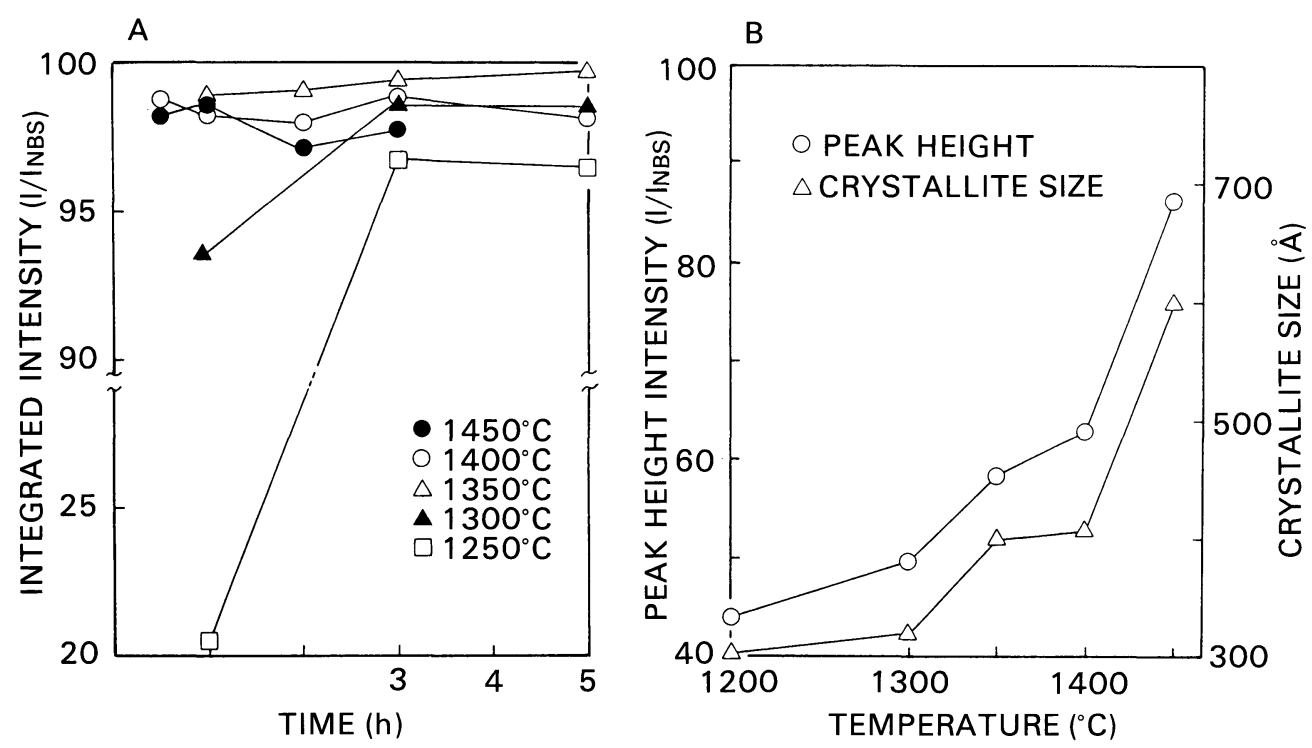

Fig. 2. A: Integrated intensity of (101) reflection of cristobalite formed from silicic acid at different temperatures, as a function of heating time. B: Change of peak height intensity of (101) reflection compared with that of NBS SRM 1879 and crystallite size of cristobalite formed at different temperatures for $3 \mathrm{~h}$.

the furnace, raise the temperature over $4-5 \mathrm{~h}$ to reach the final temperature set for each experiment. At the end of the heating, turn off the furnace and leave the crucible in the furnace to cool slowly to reach $100^{\circ} \mathrm{C}$ after about $15 \mathrm{~h}$. When the crucible is quenched rapidly to room temperature, the cristobalite content is very low. The product is ground carefully by hand in an agate mortar for a few minutes and analyzed by XRD.

The XRD analysis was done using an ordinary X-ray diffractometer with Cuk $\alpha$ radiation and equipped with a graphite monochromator. The diffraction peak selected for intensity measurement was (101) reflection $\left(21.9^{\circ}\right.$ in $\left.2 \theta\right)$ of cristobalite. Integrated intensity was measured with a scan rate of $1^{\circ} / \mathrm{min}$ from $20.0^{\circ}$ to $23.8^{\circ}$ in $2 \theta$. Relative intensity was obtained taking the corresponding intensity of the NIST (NBS) respirable cristobalite (NBS SRM 1879), which was used as a well crystalized reference mineral, to be 100 . The crystallite size of cristobalite was obtained by Scherrer's equation from the half-maximum breadth of (101) reflection. The effect of instrumental broadening was corrected by Warren's method $^{\text {9) }}$ using a single crystal of muscovite.

Preliminary experiments showed that the transformation of silicic acid to cristobalite begins at $1100^{\circ} \mathrm{C}$ and proceeds rapidly at temperatures greater than $1200^{\circ} \mathrm{C}$. The products obtained at temperatures over $1200^{\circ} \mathrm{C}$ showed a well defined XRD pattern of low-cristobalite, although each reflection of the products was somewhat broader than that of NBS SRM1879 (Fig. 1). Very weak reflec- 
tions at $20.6^{\circ}$ and $27.5^{\circ}$ in $2 \theta$ were recognized, indicating the presence of tridymite or anomalous peaks of cristobalite. ${ }^{10}$ However, the crystalline phase of each product was considered to be almost pure cristobalite. Figure 2A shows the relation between the heating time and the integrated intensity of the cristobalite obtained at different temperatures over the range $1200-1450^{\circ} \mathrm{C}$. The integrated intensities showed a maximum (more than 98\% of NBS SRM1879) after $3 \mathrm{~h}$ at temperatures greater than $1350^{\circ} \mathrm{C}$. The integrated intensity formed at $1400^{\circ} \mathrm{C}$ for $14 \mathrm{~h}$ was almost the same as that formed at $1400^{\circ} \mathrm{C}$ for $3 \mathrm{~h}$, which means that the content of cristobalite hardly increased after $3 \mathrm{~h}$. On the other hand, peak height intensity and crystallinity, i.e., crystallite size, were improved at temperatures over $1400^{\circ} \mathrm{C}$ (Fig. 2B). The crystallite size of the cristobalite prepared at $1450^{\circ} \mathrm{C}$ for $3 \mathrm{~h}$ was about $600 \mathrm{~A}$, which was nearly $80 \%$ of NBS SRM1879. Although the use of integrated intensities for quantitative XRD analysis sometimes compensates for differences or inconsistencies in crystallinity, ${ }^{2)}$ it is preferable to use a well crystallized sample as the reference mineral. Thus, conversion at $1450^{\circ} \mathrm{C}$ for $3 \mathrm{~h}$ is acceptable for making a standard cristobalite.

The following results were also obtained concerning the procedure for making cristobalite: 1) About $20 \mathrm{~g}$ cristobalite could be synthesized at one time using the procedures described above using an alumina crucible of 130-ml capacity. In this case, the temperature was raised slowly to the desired heating level taking double the time for the experiment with a few grams of silicic acid to achieve sufficient reaciton. The crystallinity of the cristobalite was almost the same as that prepared using a few grams of silicic acid. 2) The cooling rate drastically affected the formation of cristobalite: the product must be cooled slowly to room temperature at the natural cooling rate of the furnace. 3) It was necessary to employ grinding to obtain a suitable size fraction (e.g., particles of respirable size) from the product, because the product was in the form of sintered matter. To clarify the effect of grinding, sintered matter prepared at $1450^{\circ} \mathrm{C}$ for $3 \mathrm{~h}$ was crushed by hand, passed through a 325 mesh $(0.044 \mathrm{~mm})$ sieve, and then ground automatically using an Ishikawa AGA mechanical agate mortar. Integrated intensity was decreased by about $15 \%$ after 30 min grinding compared with that of the cristobalite ground for $1 \mathrm{~min}$. Mechanical grinding was necessary for a few minutes to reduce particle size for loading in an aluminum specimen holder for XRD analysis. Since the grinding effect of cristobalite seems to be marked, mechanical grinding should be completed within a few minutes.

In conclusion, the present results show that the integrated intensity of the cristobalite prepared at $1450^{\circ} \mathrm{C}$ for $3 \mathrm{~h}$ is essentially equal to that of well crystallized NBS SRM1879. Furthermore, the cristobalite showed 90\% peak height intensity (Fig. 2B) and $80 \%$ crystallite size compared with NBS SRM 1879. Lange et al. $^{6}$ ) reported that $3 \mathrm{mg}$ amorphous silica collected on a membrane filter was transformed to cristobalite after heating at $1500^{\circ} \mathrm{C}$ for $1 \mathrm{~h}$ or at $1100^{\circ}$ $\mathrm{C}$ for $6 \mathrm{~h}$ and that the XRD peak intensity was the same as that of well 
crystallized cristobalite. Although their procedure differed from that described here, reaction at $1100^{\circ} \mathrm{C}$ for $6 \mathrm{~h}$ using a few grams of silicic acid was incomplete under the present conditions.

\section{REFERENCES}

1) Bye E. Quantitative microanalysis of cristobalite by X-ray powder diffraction. J Appl Cryst 1983; 16: $21-3$

2) Chung FH. Synthesis and analysis of crystalline silica. Environ Sci Technol 1982; 16: 796-9

3) Holmquist SB, Berry TF, Zwell L. Quantitative X-ray analysis of silica minerals. Am Ceram Soc Bull 1958; 37: 317-21

4) Foster RD, Walker RF. Quantitative determination of crystalline silica in respirable-size dust samples by infrared spectrophotometry. Analyst 1984; 109: 1117-27

5) Hill VG, Roy R. Silica structures studies: V. The variable inversion in cristobalite. J Am Ceram Soc $1958 ; 41: 532-7$

6) Lange BA, Haartz JC, Hornung RW. Determination of synthetic amorphous silica in industrial air samples. Anal Chem 1981; 53: 1479-84

7) NIOSH. NIOSH technical report, preparation and characterizatin of analytical reference minerals. Cincinnati: DHEW 1979; 180

8) Verduch AG. Kinetics of cristobalite formation from silicic acid. J Am Ceram Soc 1958; $41: 427$ $-32$

9) Klug HP, Alexander LE. X-ray diffraction procedures for polycrystalline and amorphous materials. 2nd ed. New York: John Wiley \& Sons, 1974: 996

10) Walker RF, Schneider SJ, Roth RS. Some evidence for structural anomalies in pure cristobalite. J Am Ceram Soc 1959: 42: 642-3

Naitonal Institute of Industrial Health,

Yasushi SHINOHARA and

21-1, Nagao 6-chome, Tama-ku,

Norihiko KOHYAMA

Kawasaki 214, Japan

(Received March 22, 1990 and in revised form June 4, 1990) 